\title{
Klimaänderung und Gletscherskitourismus
}

\section{Einleitung}

Im vorliegenden Artikel kommt die thematische Schnittstelle zweier Forschungsprojekte zur Sprache, die im Rahmen des Nationalen Forschungsprogramms (NFP) 31 «Klimaänderungen und Naturkatastrophen» am Geographischen Institut der Universität Zürich bearbeitet werden. Beim ersten handelt es sich um das Projekt "Auswirkungen einer Klimaänderung auf den Tourismus im Alpenraum" (Projektleiter: Hans Elsasser, Projektmitarbeiter: Bruno Abegg). In diesem Projekt stellt sich zunächst einmal die Frage, wie Klima und Tourismus miteinander verknüpft sind. Das hat nichts mit «Klimadeterminismus» zu tun, sondern es geht darum, Wetter und Klima angemessen in die Tourismusdiskussion einzubeziehen. In den letzten Jahren wurde uns bekanntlich ziemlich klar vor Augen geführt, daß wir a) den klimatischen Voraussetzungen für den Tourismus wieder vermehrt Beachtung schenken sollten und b) Wetter und Klima weder konstant noch "gottgegeben" sind. In diesem Zusammenhang steht natürlich die Klima- und Wettersensibilität des Tourismus im Vordergrund. Hierzu nur ein Stichwort: die schneearmen Winter Ende der 80er Jahre. Und schließlich geht es um mögliche Szenarien, also darum, wie der Tourismus im schweizerischen Alpenraum unter veränderten klimatischen Bedingungen in Zukunft aussehen könnte. Mit dieser Frage hat sich auch Urs König in seiner Diplomarbeit auseinandergesetzt, wobei er sich allerdings auf Aspekte rund um den Gletscherskitourismus beschränkte (KÖNIG 1994). Damit ist die Verbindung zum zweiten NFP-31-Teilprojekt hergestellt, welches unter dem Titel «Die Auswirkungen von Klimaänderungen auf die Gletscher und deren Vorfelder» ganz speziell den Gletschern der Schweizer Alpen, ihren Veränderungen und Zukunftsperspektiven gewidmet ist (Projektleiter: Max Maisch, Projektmitarbeiter: Bernhard Denneler, Andreas Wipf). Dazu werden im Anschluß an eine bereits abgeschlossene Studie im Gebiet des Bündnerlandes sämtliche verbleibenden Gletscher der Walliser, Berner Oberländer und Waadtländer Alpen nach einheitlichen Richtlinien neu bearbeitet und inventarisiert. Arbeitsziel und Grundlage bilden die vollständige Rekonstruktion sämtlicher Eisflächen zur Zeit der sogenannten «Hochstandsausdehnung von 1850» sowie die glaziologische Auswertung der Veränderungen bis zur heutigen Ausdehnung (bzw. Basisjahr 1973 des offiziellen Schweizerischen Gletscherinventars, vgl. MÜLLER et al. 1976). Die neu gesammelten Rohdaten werden in einer Gletscherdatenbank abgelegt, wo die Parameter je nach Fragestellung differenziert aufbereitet werden können (z. B. Gletscherflächen sowie Volumenwerte und deren Veränderung nach Kantonen, hydrologischen Einzugsgebieten, Höhenstufen, Gebirgsgruppen, Gletschertypen usw.). Die praktische und im Konzept bewußt «zukunftsgerichtete» Nutzungsanwendung dieser Erhebungen zielt letztlich auf die Erstellung, Quantifizierung und Visualisierung möglichst präziser und regional unterscheidbarer Gletscherschwundszenarien und deren naturräumlicher Auswirkungen für das 21 . Jahrhundert ab.

\section{Der Gletscherskitourismus in der Schweiz}

In den 60er und 70er Jahren rückten die schweizerischen Gletscherregionen zusehends ins Blickfeld der Tourismusplaner. Von der Gletschererschließung versprach man sich eine Attraktivitätssteigerung des Alpenraumes für den damals rückläufigen Sommertourismus. Verschiedene Orte verfolgten diese Strategie und erschlossen ihre Gletscher für touristische Zwecke. Das Sommerskifahren kam langsam in Mode, erlebte einen Aufschwung, und mit der Zeit wurden die Gletscher auch in den Winterskibetrieb integriert. Heute hat sich das Blatt gewendet: Während der Sommerskibetrieb laufend an Bedeutung verliert, werden die Gletscher als Garanten für Schneesicherheit im Winter immer wichtiger.

Sieht man vom kleinen Skilift auf dem Jungfraujoch ab, gibt es in der Schweiz zurzeit neun Gletscherskigebiete (Zermatt, Saas Fee, Corvatsch, Diavolezza, Laax, Engelberg, Crans-Montana, Les Diablerets und Verbier). Ursprüngliche Motivation für die Erschließung dieser Gletscherskigebiete war in sieben der neun Fälle die Möglichkeit, Sommerskifahren anzubieten. Vom Sommerskibetrieb erhoffte man sich einen Imagegewinn für den Tourismusort und das Skigebiet sowie die bereits erwähnte Belebung der Sommersaison. In Crans-Montana und Laax war die Sicherung eines frühen Saisonstarts im

Bruno Abegg, dipl. Geogr., Urs König, dipl. Geogr., Max Maisch, PD Dr., Geographisches Institut der Universität Zürich Irchel, Winterthurerstraße 190, 8057 Zürich. 


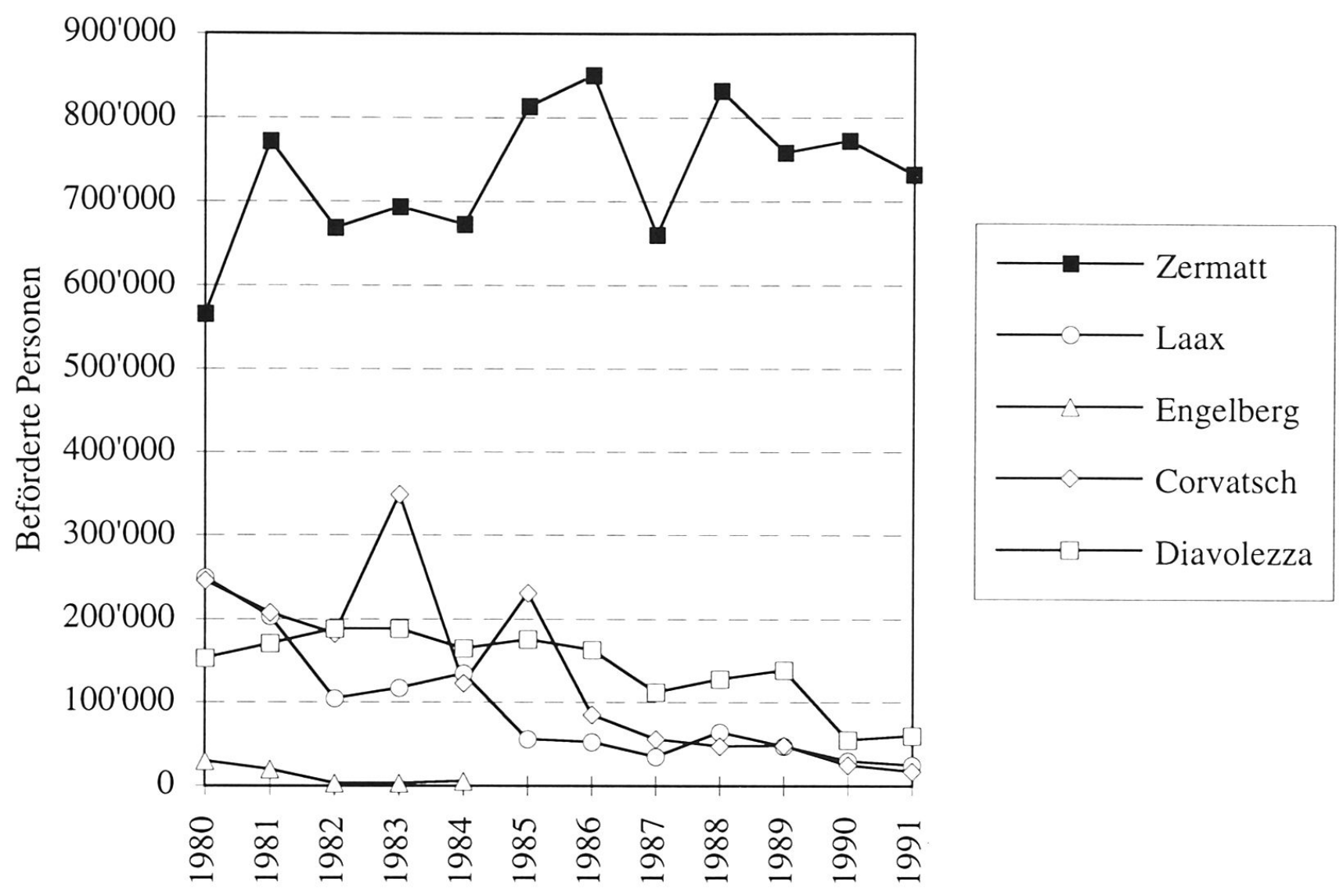

Abb.1 Sommerskifrequenzen in ausgewählten Gletscherskigebieten (Mai/Juni bis Sept./Okt.). Daten: Geschäftsberichte und interne Transportstatistiken der entsprechenden Bergbahnunternehmen.

Winter der Hauptgrund für die Erschließung des Gletschers; der Sommerski- bzw. Ganzjahresskibetrieb wurde erst später eingeführt.

Die Erwartungen, welche ins Sommerskifahren gesetzt worden sind, erfüllen sich heute nur mehr in Saas Fee und Zermatt. Die beiden größten und attraktivsten Gletscherskigebiete der Schweiz weisen anhaltend hohe Sommerfrequenzen auf und haben durch günstige Gelände- und Klimavoraussetzungen kaum Probleme mit der Ausaperung ihrer Gletscher. In den restlichen Sommerskigebieten der Schweiz führte die immer stärker werdende Ausaperung der Gletscher zur Reduktion (Crans-Montana, Verbier, Les Diablerets, Diavolezza) oder gar Aufgabe (Corvatsch, Laax, Engelberg) des Sommerskiangebotes. Obwohl der Sommerskibetrieb mit Ausnahme von Zermatt und Saas Fee in allen Gebieten mehrheitlich Verluste einbrachte und noch immer einbringt, wird er aus Imagegründen so lange wie möglich aufrechterhalten. Es wird davon ausgegangen, daß die Gäste die Existenz eines Sommerskigebietes mit Schneesicherheit im Winter assoziieren. In diesem Sinne ist das Sommerskifahren Wegbereiter für die kommende Winterskisaison.

Die abnehmenden Sommerfrequenzen sind aber nicht alleine mit den naturräumlichen Problemen zu erklären.
Es scheint, daß die Gruppe der prestigebewußten SkifahrerInnen, welche in früheren Jahren einen großen Teil der Gäste ausmachte, immer mehr verschwindet und sich anderen «trendigen» Sommersportarten zuwendet. Die auch im Sommer stetig wachsende Zahl der SnowboarderInnen kann den Rückgang der Frequenzen nicht abwenden. Hinzu kommt, daß die Abwanderung der regionalen und nationalen Skikader aus den kleinen Gletscherskigebieten in die großen Sommerskigebiete von Saas Fee und Zermatt ebenfalls zur Konzentration auf dem Sommerskimarkt beiträgt.

Während das Sommerskifahren in den kleineren Gletscherskigebieten an Stellenwert einbüßt, gewinnt die Saisonverlängerung und das Wintergletscherskifahren in allen Gletscherskigebieten an Bedeutung. Die Gletscher garantieren auch in schneearmen Frühwintern einen Saisonstart im Oktober oder spätestens im November. In den schneearmen Wintern Ende der 80er Jahre verzeichneten die Gletscherskigebiete (insbesondere Engelberg, Crans-Montana, Les Diablerets, Laax und Verbier) markante Frequenzsteigerungen, die auf Schneearmut im Rest des Skigebietes und/oder auf Schneemangel in benachbarten Skigebieten ohne Gletscher zurückgeführt werden können. Die Gletscherlifte können somit als ei- 


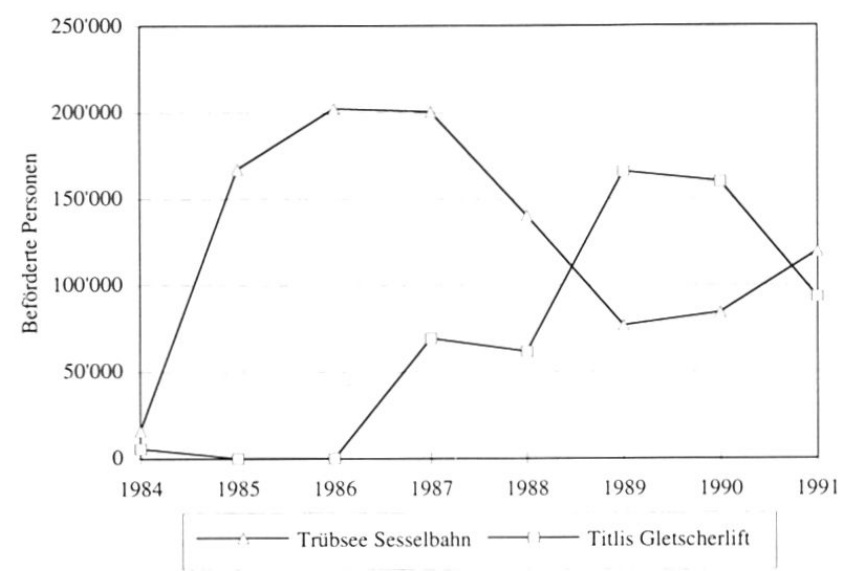

Abb. 2 Frequenzvergleich: Trübseesesselbahn - TitlisGletscherlift. Daten: Geschäftsberichte Luftseilbahnen Trübsee-Stand-Kleintitlis AG 1991 und Bergbahnen Engelberg-Gerschnialp-Trübsee AG 1991

gentliche «Retter» der Skisaison in schneearmen Wintern bezeichnet werden. Zeitweise waren sie die einzigen Anlagen, welche in Betrieb waren.

Ein eindrückliches Beispiel für diese Rettungsankerfunktion liefert der Frequenzvergleich zweier Transportanlagen in Engelberg (vgl. Abb. 2). Die Trübsee-Sesselbahn liegt auf unvergletschertem Gebiet und beförderte in Wintern, in denen genug Schnee lag, deutlich mehr Personen als der Gletscherlift. In den schneearmen Wintern Ende der 80er Jahre mußte der Betrieb der Sesselbahn häufig eingestellt werden. Die Frequenzen sanken entsprechend. Der Gletscherlift (in schneereichen Jahren nicht immer in Betrieb) gewährleistete trotz Schneemangel in den tieferen Lagen einen durchgehenden Winterskibetrieb und verzeichnete markante Frequenzsteigerungen.

Tendenziell weisen sämtliche Gletscherlifte der Schweiz in schneearmen Wintern hohe, in schneereichen tiefere Frequenzen auf. Diese «Pufferwirkung» der Gletscherlifte bewahrt die Bergbahnen vor totalen Frequenzeinbrüchen in milden Wintern. Langfristig sichert das Gletscherskigebiet dem Fremdenverkehrsort somit ein «schneesicheres Image». In diesem Sinne verfügen Wintersportorte mit Anschluß an ein Gletscherskigebiet über einen beträchtlichen Wettbewerbsvorteil. Davon profitieren natürlich auch die nachgelagerten Bereiche im Tourismus.

Die Folgen dieser Frequenzsteigerungen beim Wintergletscherskifahren sind Kapazitätsengpässe bei den Transportanlagen. Es erstaunt deshalb nicht, daß in einigen Gletscherskigebieten der Ausbau der Transportanlagen ins Auge gefaßt wird.

\section{Die Auswirkungen von Klimaänderungen auf die Gletscher}

Gebirgsgletscher werden oft als "Klimazeiger mit Langzeitgedächtnis» bezeichnet (vgl. HAEBERLI 1994). Ihre große Sensibilität gegenüber Klimaschwankungen macht die Gletscher mit Hilfe glazialmorphologischer (z. B. Moränendatierung) und paläoglaziologischer Methoden (z. B. Schneegrenzberechnungen, Klima-Gletscher-Studien) zu geeigneten Untersuchungsobjekten im Hinblick auf die Entschlüsselung früherer Klimaverhältnisse. Die mittel- bis langfristigen Dimensionsänderungen (Zeitraum Jahrzehnte bis Jahrhunderte) können im komplizierten Gefüge zwischen Klimasystem und Gletscherreaktion als Signale für Veränderungen der klimatischen Umwelt interpretiert werden. In Umkehrung der bisherigen glazialhistorisch orientierten Betrachtungsweise ist es mit geeigneter Methodik aber auch möglich, Gletscher als einfache Berechnungmodelle zur Abschätzung und Quantifizierung künftiger Klimaverschiebungen zu verwenden (vgl. KUHN 1990, HAEBERLI 1991, MAISCH 1992, HÖLZLE 1994). Gletscherströme und deren Vorfelder eignen sich zudem hervorragend zur "glazialdidaktischen" Veranschaulichung der Klimaerwärmung seit 1850 und der künftig zu erwartenden «Treibhausfolgen" (vgl. MAISCH et al. 1993). Die Erforschung der seit Mitte des letzten Jahrhunderts stark geschwundenen Alpengletscher trägt dabei wesentlich zu einer besseren Wahrnehmung der gegenwärtigen und zu einer angemesseneren Beurteilung der künftigen Klima- und Umweltproblematik bei.

\subsection{Erkenntnisse über den Gletscherschwund seit 1850}

Aufgrund der bereits ausgewerteten Gletscherdaten aus den Gebirgsgruppen des Bündnerlandes konnten für den "Jahrhundertgletscherschwund" seit 1850 einige typische glaziologische Gesetzmäßigkeiten abgeleitet werden (MAISCH 1992). Wegen ihres allgemeinen Charakters dürften die nachfolgend vereinfacht wiedergegebenen Kernaussagen wohl auch für die Szenarien des 21. Jahrhunderts gültig sein. Indirekt sind sie damit auch für die Beurteilung künftiger Entwicklungsperspektiven im Bereich des Gletscherskitourismus nicht uninteressant:

- Seit dem Hochstand von 1850 sind bei einer Erwärmung im Ausmaß von $+0,5^{\circ} \mathrm{C}\left( \pm 0,2^{\circ}\right)$ die GletscherSchnee-Grenzen (Parameter 2:1-Gleichgewichtslinie, 2:1- GWL), mit geringen niederschlagsbedingten regionalen Abweichungen, im Mittel um 80 Meter angestiegen. Dies ergibt einen empirischen Temp./GWL-Gradienten von $0,6 \% 100 \mathrm{~m}$, in guter Übereinstimmung mit theoretischen Berechnungsansätzen (KUHN 1990). Eine GWL-Erhöhung um + 100 Meter, wie sie gemäß den heute verwendeten Klimaszenarien für die nächsten 20-30 Jahre abzuleiten ist (NFP-31-Szenario A «Business as usual»: + 0,3 ${ }^{\circ} \mathrm{C}$ Erwärmung pro Jahrzehnt, NFP-31-Szenario $\mathrm{C}:+0,2{ }^{\circ} \mathrm{C}$ pro Jahrzehnt), stellt also bereits eine fünf- bis achtfache Beschleunigung des seit 1850 beob- 
achtbaren Klimawandels dar (Erwärmung um + 0,4g pro Jahrhundert!).

- Die absoluten wie relativen Beträge der Flächen- und Volumenänderungen korrelieren signifikant mit den Ausgangsdimensionen der untersuchten Gletscher: Für große Gletscher (Fläche $>10 \mathrm{~km}^{2}$, z. B. Morteratsch) und stark vereiste Gebiete (z. B. Bernina) beträgt der gletschertypische und regionale Flächenschwund in der Regel $15-30 \%$. In weniger stark vergletscherten Regionen und bei mittelgroßen Gletschern liegt der prozentuale Flächenverlust seit 1850 deutlich höher, im Mittel zwischen 40 und $60 \%$, in kaum vereisten Randlagen sogar bis $70 \%$. Etliche Firn- und Gletscherflecken sind als Folge der ungünstigen Ernährungsbedingungen sogar vollständig abgeschmolzen.

- Große Gletscher tragen, obwohl seltener vorkommend, absolut mehr zum regionalen Flächen- und Volumenschwund, zu den Abflußmengen und letztlich auch zur Vorfeldarealvergrößerung bei als die Mehrzahl der kleineren Gletscher, sie schrumpfen jedoch im Verhältnis zu ihren bedeutenderen Eis-/Wasserreserven prozentual weniger stark.

- Kleine, mit ihren Nährgebietsflächen nur wenig hoch hinaufreichende und kaum durch Karwände geschützte Gletscher reagieren auf Verschiebungen der GWL wesentlich empfindlicher und schwinden in Ungunstphasen überdurchschnittlich stark. Sie erleiden durch die Albedoveränderungen in ihrer unmittelbaren Umgebung zudem positive, den Eiszerfall beschleunigende Rückkopplungseffekte.

- Gletscher mit geringem Oberflächengefälle $\left(5-15^{\circ}\right.$ Neigung) reagieren empfindlicher auf Verlagerungen der GWL als steilere Eistopographien. Ein klimabedingtes Höherrücken der GWL bewirkt hier sofort eine existenzbedrohende Verkleinerung des Nährgebietes, was im komplementären Sinne gleichzeitig zu einer Vergrößerung des Zehrgebiets und einer Verstärkung der Ablation und damit der Schmelzprozesse in tieferen Zonen führt.

\subsection{Methodik und erste Ergebnisse der Gletscherschwundprognosen}

Es ist vorgesehen, die Gletscherschwundprognosen für den Zeitraum des 21. Jahrhunderts mit Hilfe von Schneegrenz-bzw. GWL-Anstiegsszenarien aufzustellen und in Form zeitlich hintereinander gestaffelter Karten- und Tabellensequenzen zu veranschaulichen. Diese Szenarioskizzen ermöglichen, in 100-m-GWL-Anstiegs-Schritte unterteilt, eine rasche synoptische Beurteilung der räumlich unterschiedlichen Intensität, der glaziologischen Gesetzmäßigkeiten und, mit einer zwar noch stark spekulativen Zeitskala verknüpft, auch ein Bild von der Dynamik des voraussichtlichen Eiszerfalls (Beispiel in Abb. 3).

Zur Modellierung der Schwundszenarien werden als Ausgangsdaten die hypsographischen Parameter eines jeden Gletschers benötigt (Flächen-Höhen-Verteilung).
Das hypsographische Profil wird anschließend mit Flächenteilungsverfahren kombiniert (Accumulation Area Ratio AAR = 0,67, sog. "2:1-GWL», Gleichgewichtslinie im Mittel über mehrere Jahre, welche die Oberfläche eines Gletschers im "Faustregelverhältnis» 2:1 zwischen Nähr- und Zehrgebiet teilt). Mit Hilfe dieser Szenariotechnik kann die Gletscherprognostik vorerst ausschließlich geometrisch und damit noch weitgehend «klimaunabhängig» vollzogen werden. Denn zum gegenwärtigen Zeitpunkt sind die Angaben über den Zeitraum der vorhergesagten Klimaänderung sowie über die für den Gletscherhaushalt so wichtigen Temperatur- und Niederschlagsverhältnisse noch recht pauschal und unsicher, bisweilen sogar umstritten. Die hier vorgestellten Schwundtendenzen vermögen damit lediglich einen virtuellen Ablauf vorzuzeichnen. Erst bei tatsächlich eintretender Klimaänderung vermögen sie die neu sich einstellenden Situationen plausibel zu beschreiben.

In Abb. 4 werden die Zukunftsaussichten einiger ausgewählter und im Sektor Skitourismus bekannter Gletscher in einem Szenariodiagramm dargestellt. Mit den beiden untersten Skalen (Klimaprognosen: Erwartungszeiträume) können die GWL-Anstiegsmodelle mit den bisher von der NFP-31-Projektleitung vorgeschlagenen Klimaszenarien A ("Business as usual») und C (weniger pessimistische Annahmen) kombiniert werden. Erst so ist, mit aller gebotenen Vorsicht vor einer Überinterpretation, eine durchaus realistische Beurteilung der künftigen Eiszerfallsdynamik möglich.

Es zeigt sich, und dies trifft auch für die Gesamtheit der Bündner Gletscher zu, daß die hier ausgewählten Einzelgletscher schon ab GWL-Szenario + $100 \mathrm{~m}\left(+0,6{ }^{\circ} \mathrm{C}\right.$, Zeithorizont Szenario A: 2010, Szenario C: 2020) deutlich, ab GWL-Szenario $+200 \mathrm{~m}\left(+1,2{ }^{\circ} \mathrm{C}\right.$, Zeithorizont 2030/2050) bereits markant und beschleunigt an Fläche einbüßen werden. Es kommt den Erwartungen entsprechend zum Ausdruck, daß z. B. der große und mit seinem Akkumulationsgebiet hoch hinaufreichende Feegletscher deutlich am langsamsten schwinden wird, während die Gletscher Corvatsch und Tortin bei GWL-Szenario $+400 \mathrm{~m}$, Tsanfleuron und Vorab bei GWL-Szenario + 300 m und der marginale Gletscherfleck auf der Diavolezza schon bei GWL-Szenario + 200 m ganz verschwunden sein werden.

\section{Die Zukunft des Sommerskifahrens}

Heute präsentiert sich die Situation des Sommerskifahrens in der Schweiz wie folgt:

Der Sommerskimarkt ist gesättigt. Die gesamtschweizerischen Frequenzen sind rückläufig, und die Nachfrage konzentriert sich in immer stärkerem Maße auf die beiden Gletscherskigebiete von Zermatt und Saas Fee. Die restlichen Gletscherskigebiete sehen sich gezwungen, ihr Sommerskiangebot laufend zu reduzieren, oder haben es bereits aufgegeben. Gemäß den oben aufgezeigten 
Gletscherschwund-Szenario: GWL $+300 \mathrm{~m}$; Temp.-Anstieg $+1.8^{\circ}$ Zeithorizont gemäss Szenario A: 2050, Szenario C: 2100

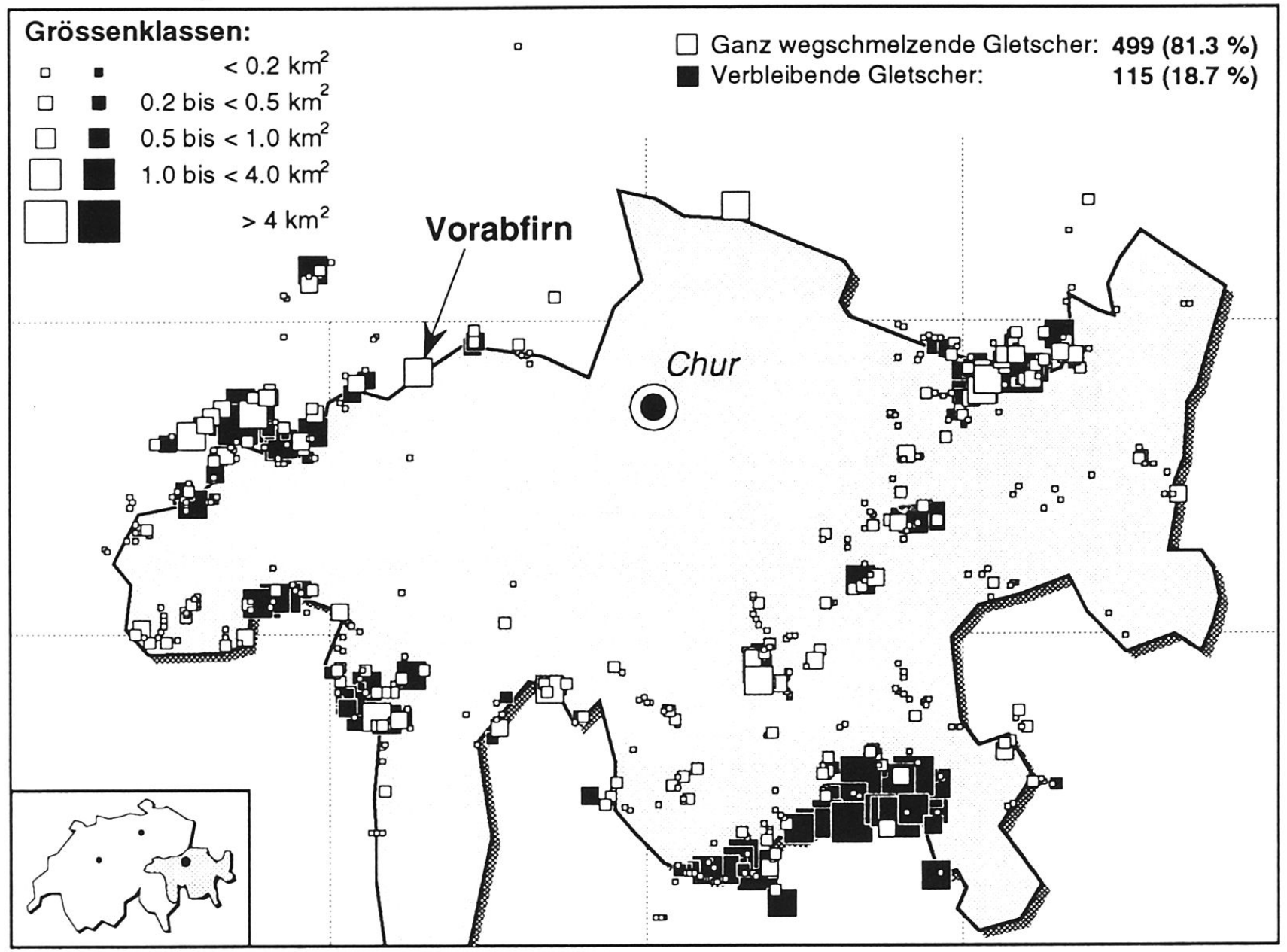

Abb. 3 Gletscherschwund-Szenario GWL + 300 m für das Bündnerland. Dargestellt sind die unter den vorgegebenen Klimabedingungen (Erwärmung um $+1,8^{\circ}$ gegenüber heute) aller Voraussicht nach vollständig wegschmelzenden (offene Rechtecke) bzw. noch verbleibenden Gletscher (schwarze Rechtecke), nach Größenklassen geordnet.

Gletscherschwundszenarien ist von einem Fortschreiten des in den letzten Jahren angelaufenen Konzentrationsprozesses auf dem Sommerskimarkt auszugehen. Längerfristig muß damit gerechnet werden, daß nur noch Saas Fee und Zermatt in der Lage sein werden, ansprechende Bedingungen für das Sommerskifahren zu gewährleisten. Die restlichen Gebiete werden ihren Betrieb aufgrund der Schwundszenarien einstellen müssen. Die in der Vergangenheit entstandenen, heute gesamtschweizerisch eher zu hohen Kapazitäten werden durch die zunehmende Ausaperung sowie den fortlaufenden Flächenverlust der Gletscher, was über kurz oder lang zum Ausscheiden einzelner Gebiete aus dem Sommerskimarkt führt, abgebaut und somit quasi automatisch der tendenziell sinkenden Nachfrage angepaßt. Trotz der sich in den letzten Jahren abzeichnenden Veränderungen in der Gästestruktur der Sommerskitouristen dürfte allerdings auch in Zukunft Sommerskifahren nachge- fragt werden. Verschiedene Bergbahndirektoren sind der Ansicht, daß ein kleiner, stagnierender Markt bestehenbleiben wird.

Für diejenigen Gebiete, die den Sommerskibetrieb einstellen müssen, bedeutet diese Entwicklung in erster Linie einen Verlust an finanzkräftigen und ausgabefreudigen Gästen. Die Aufgabe des Sommerskiangebotes hatte allerdings weder in Engelberg (1985) noch in Laax (1992) maßgeblichen Einfluß auf die Logiernächtezahl. Die Wirkung des vielleicht entscheidenderen Imageverlustes läßt sich kaum beurteilen. Die Abwanderung der Gäste von den bedrohten Sommerskigebieten nach Saas Fee und Zermatt wird auf die dortigen Frequenzen einen positiven Einfluß haben. Das Ausmaß dieser Frequenzsteigerung dürfte sich jedoch in bescheidenem Rahmen bewegen. Aber auch kleine Zuwachsraten verursachen in Saas Fee und Zermatt Probleme. Bereits heute müssen in 


\section{Gletscherschwund-Szenarien}

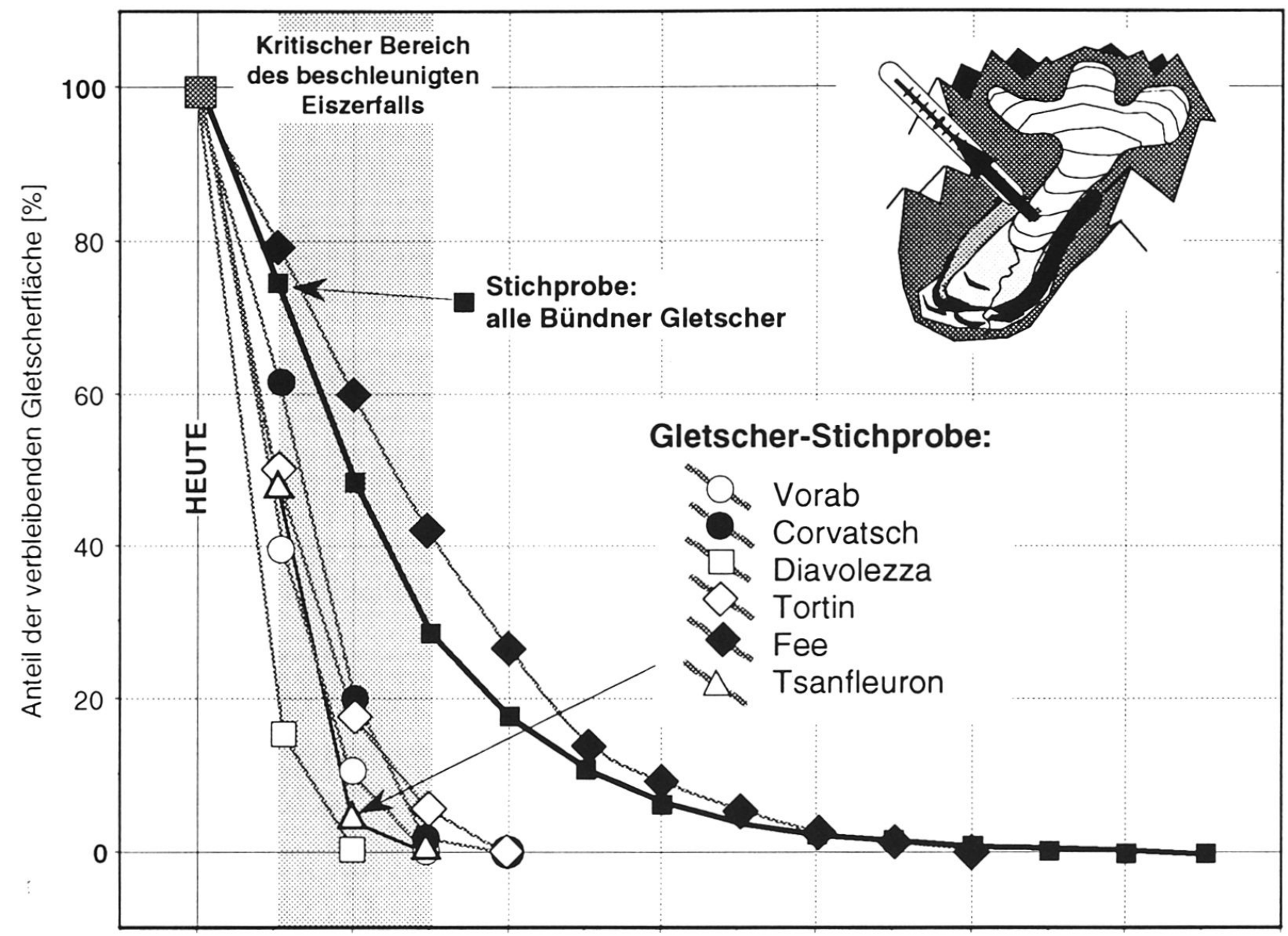

Beziehung Klima - Gletscher

Schneegrenzanstiegs-Szenarien (Meter)

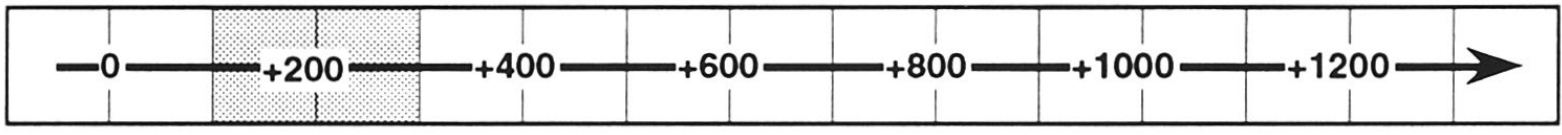

Temperaturanstiegs-Szenarien $\left({ }^{\circ} \mathrm{C}\right)$

$- \pm 0-+1^{\circ}-+2^{\circ}-+3^{\circ}-+4^{\circ}-+5^{\circ}-+6^{\circ}-+7^{\circ} \rightarrow$

Klima-Prognosen: Erwartungszeiträume

Zeithorizont Szenario A ("business as usual")

$-1990-2010-2030-2050 \longrightarrow$

\section{Zeithorizont Szenario C}

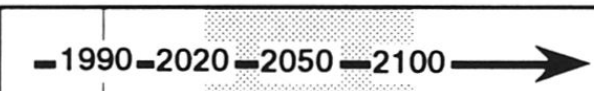

Abb. 4 Diagramm der verschiedenen Schwundszenarien für ausgewählte Gletscher mit Skitourismus im Vergleich zur Gesamtstichprobe sämtlicher Bündner Gletscher. Dargestellt sind die unter den verschiedenen GWL-Szenarien (vermutlich) noch verbleibenden Flächenanteile bzw. die "Zerfallskurven” der einzelnen Gletscher. 
beiden Gebieten wegen Platzmangels im Skigebiet Skikader abgewiesen werden. Eine weitere Zunahme der Gästezahl wird zu Kapazitätsengpässen bei den Transportanlagen und zu einer Verschärfung des schon heute kritischen Platzangebotes auf den Pisten führen. Es ist damit zu rechnen, daß in einer solchen Situation der heute noch nicht diskutierte (Zermatt) bzw. sich in bescheidenem Rahmen haltende Ausbau (Saas Fee) dieser Sommerskigebiete im größeren Stil in Betracht gezogen wird.

\section{Die Perspektiven der Gletscherskigebiete im Winter}

Die drei Winter 1987/88 bis 1989/90 waren allgemein zu warm und vielerorts äußerst schneearm. Schneearme Winter sind in der Schweiz keine Seltenheit, außergewöhnlich ist höchstens eine Abfolge von drei Wintern mit derart prekären Schneeverhältnissen. Die ungünstigen Schneeverhältnisse wirkten sich direkt auf die Nachfrage im Skitourismus aus, und es erstaunt deshalb nicht, daß in einzelnen Skigebieten beträchtliche Einbußen zu verzeichnen waren. Am schwersten getroffen hat es die Seilbahnwirtschaft (vgl. BIGA und BRP 1991; FRÖSCH und ABEGG 1993). Wird vom letzten Winter mit «normalen» Schneefällen ausgegangen (1986/87), nahmen die Umsätze in den beiden folgenden Jahren gesamtschweizerisch nur unwesentlich ab, im Winter 1989/90 sanken sie dagegen um 20\%. Arg in Bedrängnis kamen in erster Linie die mehrheitlich kleineren Unternehmen in den tieferen Lagen. Die Betriebsergebnisse waren für diese Unternehmen in allen Regionen durchwegs schlecht. Bei den meisten Betrieben in mittlerer Höhenlage gingen die Erträge ebenfalls massiv zurück. Sehr differenzierte Ergebnisse lieferten dagegen die meist großen Unternehmen, die in Höhenlagen von über $1700 \mathrm{~m}$ ü. M. operieren. Während z. B. im Berner Oberland auch bei den großen Betrieben Umsatzeinbußen von bis zu 50\% zu beklagen waren, konnten die größeren Oberwalliser und Waadtländer Unternehmen ihren Umsatz in etwa halten. In einzelnen Gebieten Graubündens (insbesondere im Engadin), im Zentralwallis und im Urnerland wurden sehr gute und z. T. Spitzenresultate erreicht. Diese Resultate sind eindeutig auf den Schneemangel in den anderen Gebieten zurückzuführen.

Die drei schneearmen Winter können zwar nicht direkt mit der globalen Erwärmung in Verbindung gebracht werden, aber sie zeigen doch sehr schön, was im Falle einer Klimaänderung passieren könnte. Gemeinhin wird davon ausgegangen, daß wir mit einem Ansteigen der winterlichen Schneegrenze rechnen müssen (vgl. z. B. FÖHN 1990). Es liegt auf der Hand, daß diese Verschiebung der Schneegrenze einen negativen Einfluß auf die Schneesicherheit der bestehenden Skigebiete haben wird. Die Schneesicherheit kann mit Hilfe der sogenannten 100-Tage-Regel beurteilt werden (WITMER et al. 1986: 193). Diese besagt, daß die Schneesicherheit und damit die Wirtschaftlichkeit eines Skigebietes nur dann gege- ben ist, wenn an mindestens 100 Tagen pro Saison eine für den Skisport ausreichende Schneedecke vorhanden ist. Heute gelten diesbezüglich die meisten Skigebiete über $1200 \mathrm{~m}$ ü. M. als schneesicher. Bei einer durchschnittlichen Erwärmung von 1 bis $2{ }^{\circ} \mathrm{C}$ ist allerdings mit einer Verschiebung dieser «Höhengrenze der Schneesicherheit» um 150 bis 300 m nach oben zu rechnen. Gemäß einer Untersuchung des Schweizerischen Verbandes der Seilbahnunternehmungen (SVS) könnten dann nur noch zwei Drittel der Schweizer Skigebiete als schneesicher bezeichnet werden; gegenwärtig sind es laut SVS noch 87\% (PFUND 1993: 10). Falls dieses Szenario eintritt, wären wir mit einem neuen Mosaik skitouristischer Gunst- und Ungunsträume konfrontiert. Die Skigebiete würden sich zusehends auf die hochgelegenen und schneesicheren Regionen konzentrieren, während die Wintersportbetriebe im Jura und in den Voralpen früher oder später aus dem Markt ausscheiden müßten. Die Talabfahrt wäre in den meisten Tourismusorten nicht mehr gewährleistet, und selbst die hochgelegenen Skiorte müßten mit einer kürzeren Saisondauer rechnen. Die wirtschaftlichen Auswirkungen für die Seilbahnwirtschaft wären ähnlich wie im Ausnahmewinter 1989/90 (vgl. oben); mit dem Unterschied allerdings, daß es für die gefährdeten Betriebe laufend schwieriger wird, schlechte mit guten Jahren zu kompensieren. Hinzu kommt, daß im Gegensatz zu den schneearmen Wintern Ende der 80er Jahre die ungünstigen Schneebedingungen voll auf die Beherbergungszahlen durchschlagen werden. Übernachtungen, die nämlich damals in Erwartung der Schneefälle noch gebucht wurden, würden bei anhaltend marginalen Schneeverhältnissen wegfallen.

Die Gletscherskigebiete, naturgemäß am höchsten gelegen und damit am schneesichersten, werden in diesem Verdrängungswettbewerb eine wichtige Rolle spielen. Die warmen Winter Ende der 80er Jahre haben gezeigt, welche Bedeutung den skifahrerisch erschlossenen Gletschern bei Schneearmut in tieferen Lagen zukommt. Ob ein Tourismusort unter veränderten klimatischen Bedingungen weiterhin als Wintersportort existieren kann, wird unter anderem von der Höhenerstreckung des Skigebietes abhängen bzw. davon, ob Anschluß an ein Gletscherskigebiet gefunden wird oder nicht. In diese Richtung weist auch der seit einigen Jahren zu beobachtende Trend, wonach Seilbahnunternehmen ihre Ergänzungsund Neuanlagen in möglichst hoch gelegenen Gebieten bauen (vgl. z. B. die Schilthornbahn AG). Gleiches gilt für den Ersatz von Skiliften durch bodenunabhängige Anlagen. Der Druck auf die Hochgebirgsregionen dürfte in Zukunft also zunehmen, denn zumindest mittelfristig stellt die Erschließung neuer oder der Ausbau bestehender Wintergletscherskigebiete eine denkbare Strategie dar, um den Skitourismus in seiner Bedeutung für die Schweiz zu erhalten. Zurzeit sind die Hochgebirgsregionen der Schweiz relativ gut geschützt. Die entsprechenden Bestimmungen in der Luftseilbahn-Konzessionsverordnung (insbes. Art. 7) werden beispielsweise derart ausgelegt, dass Neuerschließungen im Hochgebirge kaum möglich sind. Aus Tourismuskreisen wird aller- 
dings bereits der Ruf nach einer Änderung dieser Praxis laut, womit die Konfrontation mit Natur- und Landschaftsschützern programmiert ist.

Da das Ansteigen der winterlichen Schneegrenze den Gletscherskigebieten einen Wettbewerbsvorteil bringt, ist bei ungünstigen Schneeverhältnissen in tiefen Lagen mit Frequenzsteigerungen in den Gletscherskigebieten zu rechnen. Diese könnten zu Kapazitätsengpässen führen, was zu einem weiteren Wachstumsschub Anlaß geben dürfte. Als Konsequenz ist mit einem Ausbau der bestehenden Gletscherskigebiete zu rechnen. Das Ausmaß des zu erwartenden Nachfragedruckes auf die einzelnen Gletscherskigebiete ist abhängig von:

- der skifahrerischen Attraktivität des Gletscherskigebietes heute bzw. den Ausbaumöglichkeiten des Gletscherskigebietes,

- der Lage (Distanz zum nächsten schneesicheren Skigebiet, evtl. Gletscherskigebiet) sowie der Schneesicherheit der umliegenden Skigebiete.

Mit Hilfe dieser Größen läßt sich die zukünftige Nachfrage nach Wintergletscherskifahren in den Gletscherskigebieten skizzieren. Insbesondere die isolierten Gletscherskigebiete, welche von einer Vielzahl von gefährdeten Skigebieten umgeben sind, haben in Zukunft mit einem starken Zustrom von SkitouristInnen zu rechnen. Zum Abschluß wird die Situation des Gletscherskigebietes Les Diablerets detaillierter dargestellt. Mit der Superskiregion Gstaad ist es von einer Vielzahl von tief gelegenen Skigebieten umgeben und hat deshalb mit starken Frequenzsteigerungen zu rechnen.

\section{Das Beispiel Les Diablerets}

"Unterhalb von $1500 \mathrm{~m}$ ï. M. konnten kaum mehr gute Schneeverhältnisse angeboten werden, und unsere Tagesgäste suchten in dieser Situation schneesichere Skigebiete auf. Glücklicherweise können wir auf den Gletscher basieren, welcher eine sehr gute Saison und ausgezeichnete Schneeverhältnisse aufwies.» (JAHRESBERICHT VEREINIGUNG DER BERGBAHNEN VON GSTAAD UND UMGEBUNG 1992/1993, Bericht des Präsidenten)

1964 wurden die drei Sektionen der Seilbahn vom Col du Pillon auf den Glacier de Tsanfleuron fertiggestellt. Ursprünglich war die Bahn für den Aussichtsverkehr im Sommer gedacht. Bald nach Beendigung des Baues verlangte die Hotellerie der Region (Les Diablerets, Gsteig, Gstaad) aber eine Erschließung des Gletschers für das Sommerskifahren. 1971 erfolgte der Bau des ersten Skiliftes. Gleichzeitig wurde auf dem Gletscher eine Langlaufloipe gespurt. 1977 wurde die Sesselbahn eröffnet, und 1983 kam ein zweiter Skilift hinzu.

Die Sommerskifrequenzen waren von Beginn weg unbedeutend (vgl. Abb. 5). 1986 sorgte schlechtes Wetter für einen Frequenzeinbruch während der Herbstmonate. Der Rückgang der Herbstfrequenzen in jüngster Zeit ist mit der zunehmenden Ausaperung zu erklären. Bis 1988

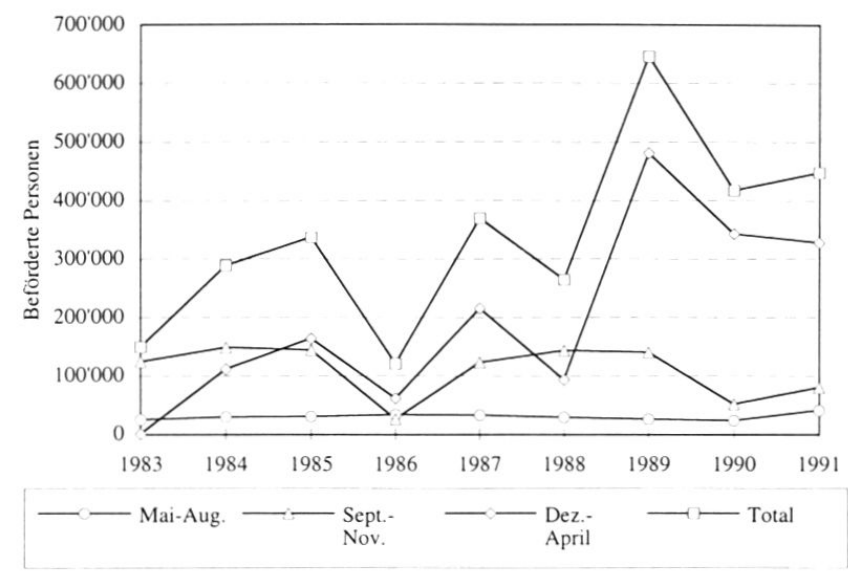

Abb. 5 Frequenzen im Gletscherskigebiet Les Diablerets (bis und mit 1988: Mai/Juni bis Dez.; ab 1988: ganzes Kalenderjahr). Daten: Téléphériques du Glacier des Diablerets SA (unveröff. Transportstatistik).

war der Gletscher vom Januar bis Mai/Juni geschlossen. In dieser Zeit waren die Transportzahlen des Monates Dezember für die Frequenzen der Wintermonate und damit auch für das Gesamtergebnis entscheidend. Der Dezember 1987 erreichte beispielsweise wegen Schneemangels im Rest des Skigebietes viermal so hohe Besucherzahlen wie der zweitstärkste Monat im selben Jahr. Der Gletscher sicherte also einen frühen Saisonstart. Seit dem Winter 1988/89 sind die Anlagen wegen Schneearmut in den tieferen Lagen den ganzen Winter in Betrieb. Der Gletscher entwickelte sich zum eigentlichen Ersatzskigebiet für die gesamte Superskiregion Gstaad. Der Verkehrsverein Gstaad verlegte gewisse Aktivitäten wie Plauschskirennen und Skiakrobatikvorführungen auf den Gletscher, so daß das "ewige Eis» im Diableretsgebiet zum skitouristischen Dreh- und Angelpunkt für Gstaad wurde. Ohne Gletscherskigebiet wäre der Logiernächteverlust in Gstaad laut Verkehrsdirektor H. Tschanz in den letzten Wintern weit größer ausgefallen. Der Ansturm der SkifahrerInnen auf den Gletscher bringt aber auch Probleme mit sich. Die nur für das Sommerskifahren und den Ausflugsverkehr konzipierte Transportkapazität der Zubringerbahn führt zu langen Wartezeiten und entsprechender Verärgerung der SkifahrerInnen. Die touristische Infrastruktur im Skigebiet (Skilifte, Restaurationsbetriebe) ist an Spitzentagen völlig überlastet. Das Wasser beispielsweise muß mit der Zubringerbahn in die Bergstation geführt werden, so daß jede zweite Gondel Wassertanks statt SkifahrerInnen transportiert. Im übrigen ist Les Diablerets das einzige Gletscherskigebiet der Schweiz, welches seine Abwässer nicht in einer Kläranlage reinigt, sondern lediglich in einer Sickergrube entsorgt. Die Überlastung der Grube führt dazu, daß Toiletten- und Küchenabwässer ungeklärt ins Tal fließen.

Vor diesem Hintergrund erstaunt es nicht, daß ein Ausbau des Gletscherskigebietes Les Diablerets geplant ist. 
Der Gstaader Verkehrsdirektor Tschanz: «Ich denke sehr ungern daran, was passiert, wenn wir im Tal keinen Schnee mehr haben; aber wir sind voll am Planen, um uns darauf vorzubereiten. Wir haben nur eine Alternative; wir müssen den Glacier ausbauen. Mit einem effizienten Zubringer und einer besseren Erschließung des riesigen Diableretsgebietes ist Gstaad weitgehend gerettet» (zit. aus: WIENER 1992). Ein 60-Millionen-Projekt, das mit einer Metro die Zubringerkapazität erhöhen sollte, wird vorerst aus Kostengründen nicht mehr weiterverfolgt. Dagegen wurde einem Konzessionsgesuch für einen neuen Skilift auf dem Gletscher entsprochen. Der 1993 erstellte Lift ist seit Februar 1994 in Betrieb.

In welchem Ausmaß hat sich nun der hier näher zur Diskussion stehende Tsanfleurongletscher bereits zurückgebildet, und wie sind seine Zukunftsaussichten im «Treibhausklima» des 21. Jahrhunderts zu beurteilen? Der Glacier de Tsanfleuron stellt den Hauptteil einer kalottenartig ausgebreiteten Gletschermasse dar, welche sich im Grenzbereich der Kantone Wallis, Waadt und Bern zwischen Oldenhorn (Becca d'Audon, 3122,5 m) und dem Gebirgsstock Les Diablerets (höchster Punkt 3209 m) auf einer plateauähnlichen und wenig ablationsgeschütz- ten Verflachung mit gegen Osten ausgerichteter Exposition erstreckt (vgl. Abb. 7). Um die Mitte des letzten Jahrhunderts war der Tsanfleurongletscher durch seine weit und ausgeprägt flächenhaft gegen Osten, in Richtung Col du Sanetsch (2251 m) vorgeschobene Zungenposition noch annähernd $7,2 \mathrm{~km}^{2}$ groß. Durch den augenfällig starken Rückgang seit Mitte des letzten Jahrhunderts ist im Vorfeld des Glacier de Tsanfleuron aus glazialmorphologischer Sicht eine besonders reizvolle und in ihrer Formenvielfalt wohl einzigartige Hochgebirgskarstlandschaft zum Vorschein gekommen (vgl. GARDAZ 1992). Das Ausmaß des Schwundes kann in bezug auf die 1850er Gletscherausdehnung absolut wie relativ als überdurchschnittlich groß bezeichnet werden. Durch den Rückgang sind $3,4 \mathrm{~km}^{2}$ oder $47 \%$ des ursprünglichen Areals verlorengegangen. Der Gletscher ist damit auf $3,8 \mathrm{~km}^{2}$ geschrumpft. Im Durchschnitt haben vergleichbare Gletscher in der Größenklasse 4-10 km² im Mittel der Einzelwerte nur gerade 20\% ( $\pm 5 \%$ ) ihrer ehemaligen Fläche verloren. Der Glacier de Tsanfleuron zeigt damit ein ähnlich starkes Schwundverhalten, wie es typischerweise eher für kleine Gletscher in der Klasse 0,2 bis $0,5 \mathrm{~km}^{2}$ charakteristisch ist (mittlerer Flächen-

\section{Tsanfleurongletscher}

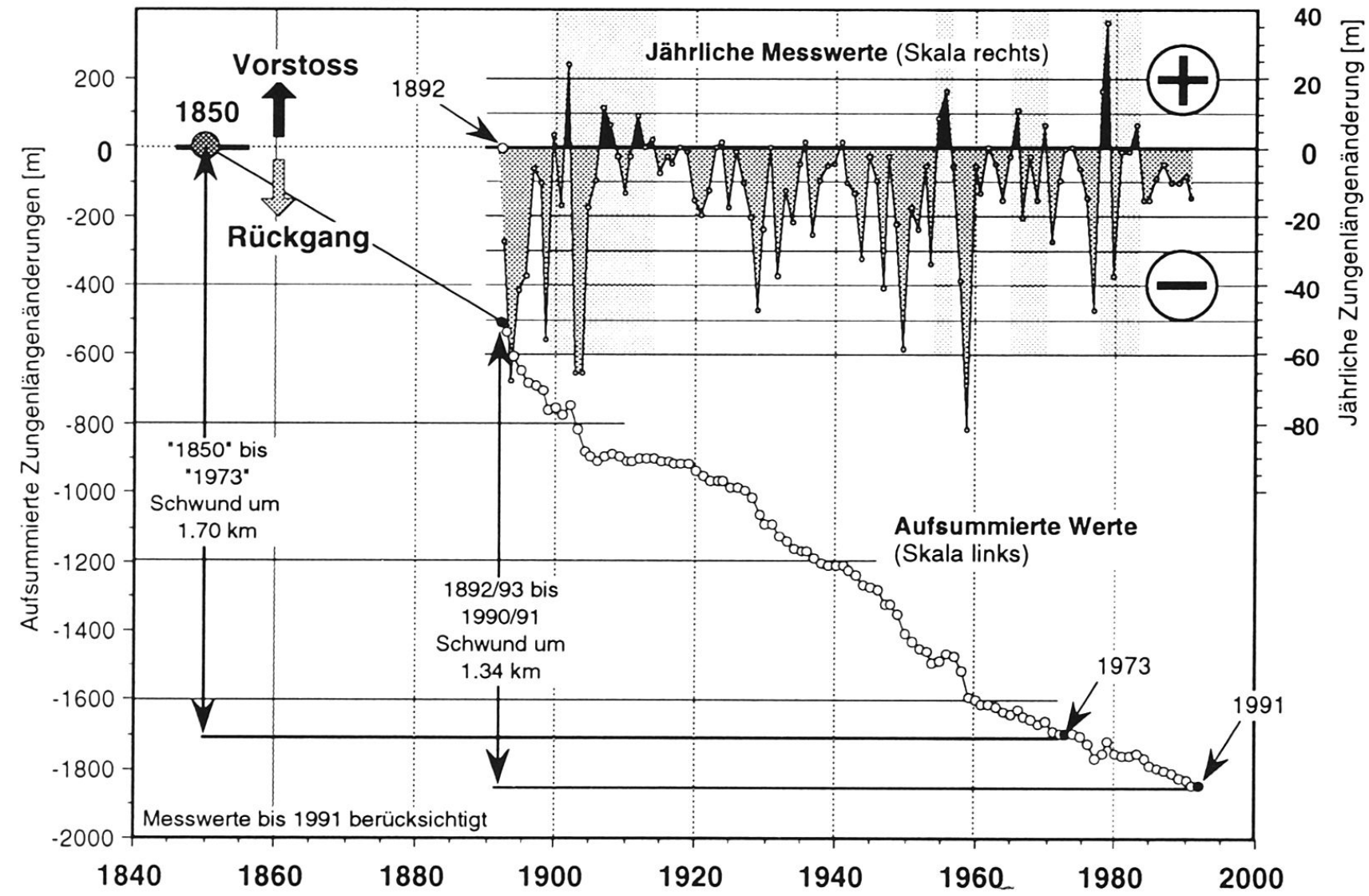

Abb. 6 Graphik der Zungenlängenänderungen des Tsanfleurongletschers. Dargestellt sind die jährlichen Meßwerte (oben, Skala rechts) sowie der Linienzug der aufsummierten, bis 1850 zurückverlängerten Meßdaten (Quelle: KASSER et al. 1986, Daten bis 1980; Quartalshefte DIE ALPEN, Daten 1981-1991). 


\section{GLACIER DE TSANFLEURON Gletscherausdehnung "Heute"}

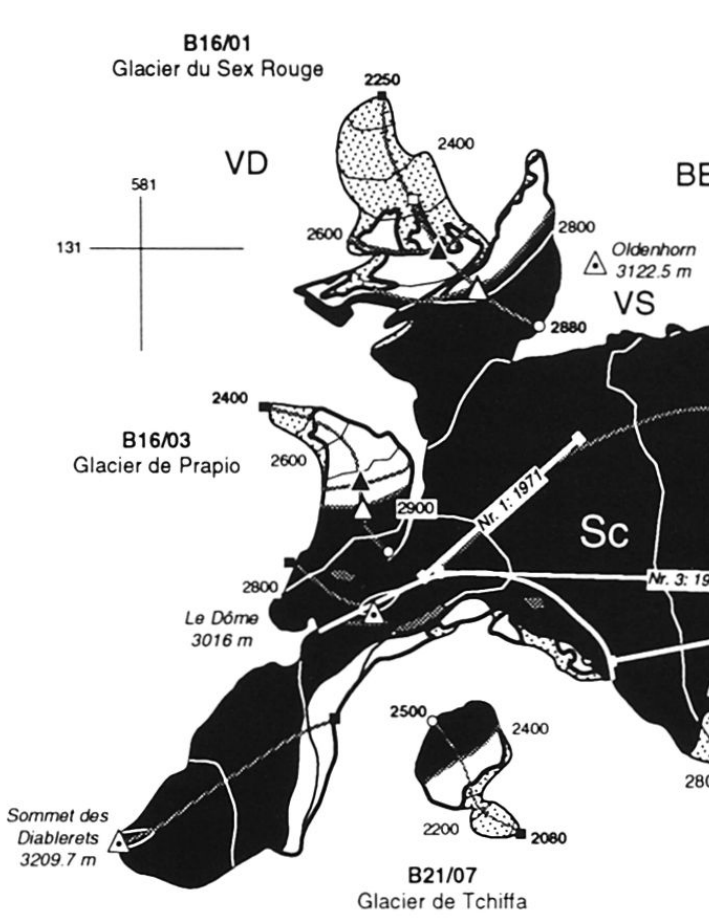

$\begin{array}{lc}\text { Fläche 1850: } & 7.18 \mathrm{~km}^{2} \\ \text { Fläche Heute: } & 3.81 \mathrm{~km}^{2} \\ \text { Verlust zu heute: } & -3.37 \mathrm{~km}^{2} \\ \text { Proz. Verlust: } & -47 \% \\ \text { 2:1-GWL Heute: } & 2715 \mathrm{~m} \\ \text { GWL-Anstieg: } & +135 \mathrm{~m}\end{array}$

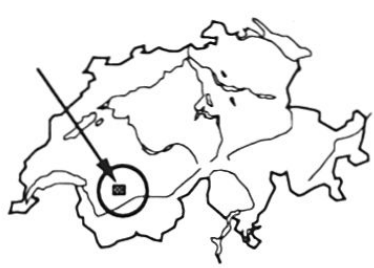

BE GWL Heute
$2715 \mathrm{~m}$$\quad$ GWL 1850

Abb. 7 Glaziologische Kartenskizze des Tsanfleurongletschers und der benachbarten Eisflächen im Gebiet Les Diablerets. Dargestellt sind die Hochstandsausdehnungen von 1850, die seit 1850 eisfrei gewordenen Vorfeldareale sowie die heutigen Gletscherflächen (unterteilt in Nähr- und Zehrgebiet). Original der 1850er Rekonstruktion von dipl. geogr. Andreas Wipf, «heutige» Ausdehnung gemäß Originalkarten des Schweizerischen Gletscherinventars 1973, vgl. MÜLLER et al. 1976.

schwundanteil bei $46,4 \%$ ). Im selben Zeitraum hat der Glacier de Tsanfleuron $1,7 \mathrm{~km}$ oder fast einen Drittel $(31,5 \%)$ seiner einstigen Länge $(5,4 \mathrm{~km})$ eingebüßt; Werte, die ebenfalls auffallend weit oberhalb der üblichen Bandbreite ähnlich großer bzw. ähnlich langer Gletscher liegen. Das Längsprofil des Tsanfleurongletschers kann zwar als ausgeglichen, sein Gefälle jedoch mit 7,7g (um 1850) bzw. 8,8g (heute) als vergleichsweise sehr gering bezeichnet werden, liegen doch die Parameter ähnlicher Gebirgsgletscher in der Größenordnung von 20,4g (um 1850) bzw. 22,6g (1973). Allein dieses topographische Merkmal vermag den soeben geschilderten außergewöhnlich markanten Flächen- und Längenverlust seit 1850 "glazialgeometrisch" gut zu erklären.

Seit 1892 figuriert der Tsanfleurongletscher (vgl. Abb. 6) im Beobachtungsnetz der Schweizerischen Gletscherkommission (vgl. KASSER et al. 1986). Die im Zeitraum 1892/93-1990/91 registrierten Meßwerte (1992 konnte keine Messung ausgeführt werden, vgl. AELLEN 1993) ergeben eine aufsummierte Längenveränderung von rund - 1340 m. Im Mittel der 99 bisherigen Registrierungen ergibt sich ein jährlicher Nettoschwundbetrag von $-13,5$ m. 77 Beobachtungsjahre wiesen negative (im Schnitt $-19,8 \mathrm{~m}$ ), 16 Jahre positive (im Schnitt $+9,8 \mathrm{~m}$ ) und sechs Jahre Nullwerte, also stationären Charakter auf. Der größte Rückgangsbetrag wurde 1959 mit -82 m, der maximale Vorstoßbetrag 1979 mit + 36 m verzeichnet. Für den Zeitraum vor Meßbeginn (1850 bis 1892) kann ein Schwundbetrag von 506 Metern «zurückgerechnet» werden. Damit hat der Tsanfleurongletscher zwischen 1850 und 1991 insgesamt 1846 m verloren, was einem mittleren jährlichen Schwundbetrag von -13,1 m entspricht. Eine wegen der sinkenden Reaktionszeit des Gletschers zwar als wenig wahrscheinlich zu bezeichnende "lineare» Fortschreibung der bisher registrierten Schwundbeträge ergäbe bei einer heutigen Restlänge von $3,7 \mathrm{~km}$ ein vollständiges Abschmelzen des Gletschers in rund 280 Jahren.

Das geringe Eisoberflächengefälle, das schmale Höhenintervall zwischen dem höchsten (3016 m ü.M.) und dem tiefsten Gletscherpunkt (Zungenhöhe 1973 auf $2440 \mathrm{~m}$ ü. M.) und die daraus resultierende ungünstige, d. h. gegenüber GWL-Verschiebungen sehr anfällige Eistopographie lassen den Tsanfleurongletscher eindeutig als einen sehr sensibel und schnell reagierenden Eiskörper beurteilen. In Abb. 7 sind für den Tsanfleurongletscher und die Eisflächen in seiner unmittelbaren Nach- 

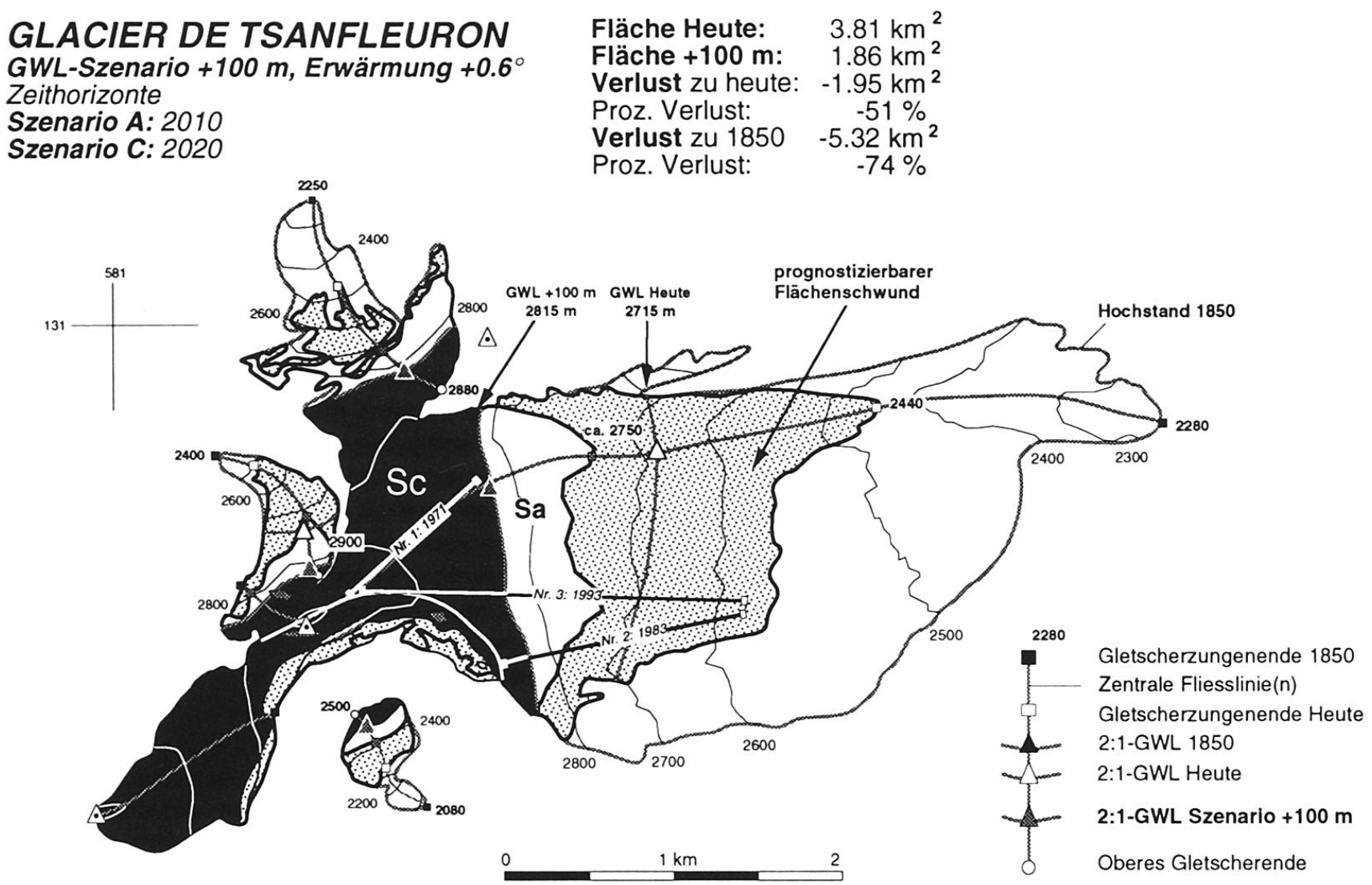

Abb. 8 Prognostische Kartenskizze des Tsanfleurongletschers bei GWL-Szenario $+100 \mathrm{~m}$ (Temperaturerhöhung + 0,6 ${ }^{\circ} \mathrm{C}$, Zeithorizont Szenario A: 2010, Szenario C: 2020). Dargestellt ist die mutmaßliche Gletscherausdehnung bei einer um 100 Meter höher gelegenen Gleichgewichtslinie und das durch den zusätzlichen Schwund neu eisfrei werdende Vorfeldareal.

barschaft die 1850er Umrisse, die heutige Ausdehnung (unterteilt in Nähr- und Zehrgebietsflächen) und damit auch gleichzeitig die Flächeneinbußen seit 1850 dargestellt. In Abb. 8 wurde mit Hilfe der hypsographischen Modellierung versucht, in hypothetischer Form den $\mathrm{Zu}$ stand für das GWL-Szenario $+100 \mathrm{~m}$ zu veranschaulichen (Temperaturerhöhung $+0,6 \mathrm{gC}$, Zeithorizont Szenario A: 2010, Szenario C: 2020). Wenn sich die Klimaprognosen erfüllen und der Gletscher durch Flächen-, Längen- und Massenreduktion in ein neues Gleichgewicht findet, wird er weitere 50 Prozent seiner heutigen Dimensionen eingebüßt haben. Die Talstationen und beträchtliche Streckenabschnitte der Skilifte Nr. 2 (Baujahr 1983) und Nr. 3 (1993) liegen dann bereits außerhalb des Gletschers. Die Talstation des Liftes Nr. 1 (Baujahr 1971) befindet sich dann gerade im Höhengürtel der sich neu einstellenden 2:1-GWL (auf gut $2800 \mathrm{~m}$ ), welcher selbst in klimatischen «Normaljahren» (bei ausgeglichener Massenbilanz, Akkumulation $=$ Ablation ) nur noch knapp im ganzjährig schneebedeckten Akkumulationsgebiet des Gletschers liegen wird. In negativen Bilanzjahren mit Netto-Massenverlusten, deren Anzahl im Zuge der angekündigten Klimaverschiebung ja zunehmen dürfte, wird die sommerliche Ausaperung weit über die Skiliftanlagen hinausreichen und somit den Sommerskibetrieb aus gletscherkundlicher Sicht sehr stark einschränken.

Mit dem Sommerskifahren auf dem Glacier de Tsanfleuron dürfte also gemäß unseren Szenarien bald Schluß sein. Das Zurückschmelzen des Gletschers wird aber auch den Winterskibetrieb negativ tangieren (Verankerung der Skiliftanlagen, Trassee- und Pistenführung usw.). Nichtsdestotrotz hat das Gletscherskigebiet Les Diablerets prinzipiell gute Zukunftsaussichten, zumindest in bezug auf den Winterskitourismus. Les Diablerets ist das einzige hochgelegene Skigebiet, welches von den SkitouristInnen der Region Gstaad für einen Tagesausflug innert nützlicher Frist erreicht werden kann. Durch seine isolierte Lage, d. h. das Fehlen anderer hochgelegener Skigebiete sowie die große Zahl von stark gefährdeten Skigebieten in unmittelbarer Nähe, ist in schneearmer Zukunft mit einer großen Nachfragekonzentration auf dem Gletscher zu rechnen:

- Kurzfristig wird der Gletscher als Ausweichvariante für die noch bestehenden Skigebiete der Superskiregion Gstaad eine wichtige Rolle spielen. 
- Mittelfristig werden nur noch einige höher gelegene Bahnen der Region in Betrieb sein. Die tiefer gelegenen Transportanlagen müssen ihren Betrieb wegen Schneemangels einstellen. Die meisten SkitouristInnen aus der Superskiregion Gstaad werden auf den Gletscher von Les Diablerets ausweichen.

- Langfristig ist denkbar, daß sich praktisch der gesamte Skibetrieb der Region auf dem Glacier de Tsanfleuron abspielen wird.

\section{Literatur}

AELLEN, M. (1993): Die Gletscher der Schweizer Alpen im Jahr 1991/1992. Auszug aus dem 113. Bericht der Gletscherkommission der Schweiz. Akad. der Naturwiss. (GK/ SANW). In: Die Alpen. Zeitschr. des Schweiz. Alpenclubs, Jg 69, 4. Quartal, 212-233.

BIGA (Bundesamt für Industrie, Gewerbe und Arbeit) und BRP (Bundesamt für Raumplanung), (1991): Beschneiungsanlagen. Neue Ausrichtung der Bundespolitik, Bern.

DIE ALPEN: Zeitschrift des Schweiz. Alpenclubs. Quartalshefte, Jahrgänge 1980-1993.

FÖHN, P. (1990): Schnee und Lawinen. Int. Fachtagung über Schnee, Eis und Wasser der Alpen in einer wärmeren Atmosphäre, 11. Mai 1990 in Zürich, Mittlg. VAW-ETH Zürich Nr. 108, 33-48.

FRÖSCH, R., und ABEGG, B. (1993): Klimaänderung und Tourismus. Auswirkungen auf die touristischen Transportanlagen, In: Regio Basiliensis, Basler Zeitschr. für Geographie, Jg. 34, Heft 1, 37-44.

GARDAZ, J.-M. (1992): Approche géomorphologique d'un complexe karstique partiellement englacé: l'exemple de Tsanfleuron (Valais/Suisse). Travail de diplôme, Institut de Géographie, Fac. des Sciences, Univ. de Fribourg.

HAEBERLI, W. (1991): Alpengletscher im Treibhaus der Erde. In: Regio Basiliensis, Basler Zeitschr. für Geographie, Jg. 32, Heft 2, 59-72.
HAEBERLI, W. (1994): Schwund der Alpengletscher und globaler Treibhauseffekt. Kurzfassung des Vortrages an der Etzelzusammenkunft (5. Dez. 1993). In: Die Alpen, Zeitschr. des Schweiz. Alpenclubs, Jg. 70, 4. Quartal, 174-177.

HÖLZLE, M. (1994): Permafrost und Gletscher im Oberengadin. Grundlagen und Anwendungsbeispiele für automatisierte Schätzverfahren. Diss. ETH Nr. 10521.

KASSER, P., AELLEN, M., und SIEGENTHALER,H. (1986): Die Gletscher der Schweizer Alpen 1977 / 78 und 1978/79 (Jubiläumsband, 99. und 100. Bericht). Glaziologisches Jahrbuch der Gletscherkommission SNG, hrsg. von der VAW/ETHZ.

KÖNIG, U. (1994): Entwicklung und Zukunft des Gletscherskitourismus in der Schweiz. Wirtschaftsgeographie und Raumplanung Vol. 19, Geogr. Institut der Univ. Zürich.

KUHN, M. (1990): Energieaustausch Atmosphäre - Schnee und Eis. Int. Fachtagung über Schnee, Eis und Wasser der Alpen in einer wärmeren Atmosphäre, 11. Mai 1990 in Zürich. Mittlg. VAW-ETH Zürich Nr. 108, 21-32.

MAISCH, M. (1992): Die Gletscher Graubündens. Rekonstruktion und Auswertung der Gletscher und deren Veränderungen seit dem Hochstand von 1850 im Gebiet der östlichen Schweizer Alpen (Bündnerland und angrenzende Regionen). Teil A: Grundlagen - Analysen - Ergebnisse (320 S.); Teil B:Verzeichnisse - Datenkataloge - Gletscherkarten (120 S.). Phys. Geographie, Vol. 33, Geogr. Institut der Univ. Zürich. MAISCH, M. (1993): Verstärkter Gletscherschwund in den Bündner Alpen. In: Cratschla, Mittlg. aus dem Schweiz. Nationalpark, 1. Jg., Heft 2, 14-26.

MAISCH, M., BURGA, C., und FITZE P. (1993): Lebendiges Gletschervorfeld. Von schwindenden Eisströmen, schuttreichen Moränenwällen und wagemutigen Pionierpflanzen im Vorfeld des Morteratschgletschers. Führer und Begleitbuch zum Gletscherlehrpfad Morteratsch. Gemeinde Pontresina, Geogr. Institut der Univ. Zürich, Engadin-Press, Samedan.

MÜLLER, F., CAFLISCH, T., und MÜLLER, G. (1976): Firn und Eis der Schweizer Alpen, Gletscherinventar. ETH Zürich, Publ. Nr. 57 und 57a.

PFUND, C. (1993): Die Seilbahnen in Zahlen. Referat an der 23. Generalversammlung des Schweizerischen Verbandes der Seilbahnunternehmungen am 16. Sept. 1993 in Champéry, unveröff. Manuskript.

WIENER, D. (1992): Wir können ja die Berge nicht höher machen, BUWAL Mediendienst (Hrsg.), In: Um-welt Schweiz, Nr. 1.

WITMER, U., et al. (1986): Erfassung, Bearbeitung und Kartierung von Schneedaten in der Schweiz. Geographica Bernensia G 25, Geogr. Institut der Univ. Bern.

Bruno Abegg, dipl. Geogr., Urs König, dipl. Geogr., Max Maisch, PD Dr., Geographisches Institut der Universität Zürich Irchel, Winterthurerstraße 190, 8057 Zürich. 